REVIEW

This paper is dedicated to the $70^{\text {th }}$ anniversary of the founding of Physiologia Bohemoslovaca (currently Physiological Research)

\title{
Eye Pupil - A Window into Central Autonomic Regulation via Emotional/Cognitive Processing
}

\author{
Nikola FERENCOVA ${ }^{1,2}$, Zuzana VISNOVCOVA ${ }^{1,2}$, Lucia BONA OLEXOVA ${ }^{2,1}$, Ingrid \\ TONHAJZEROVA ${ }^{2,1}$
}

${ }^{1}$ Biomedical Center Martin, Jessenius Faculty of Medicine in Martin, Comenius University in Bratislava, Martin, Slovak Republic, ${ }^{2}$ Department of Physiology, Jessenius Faculty of Medicine in Martin, Comenius University in Bratislava, Martin, Slovak Republic

Received June 19, 2021

Accepted October 12, 2021

\section{Summary}

If the eyes are windows into the soul, then the pupils represent at least the gateway to the brain and can provide a unique insight into the human mind from several aspects. The changes in the pupil size primarily mediated by different lighting conditions are controlled by the autonomic nervous system regulated predominantly at the subcortical level. Specifically, parasympathetically-linked pupillary constriction is under the Edinger-Westphal nucleus control and sympathetically-mediated pupillary dilation is regulated from the posterior hypothalamic nuclei. However, the changes in the pupil size can be observed at resting state even under constant lighting, these pupillary changes are mediated by global arousal level as well as by various cognitive factors. In this context, autonomic pathways modulating changes in the pupil size in response to the different light levels can be influenced by multiple central descending inputs driving pupillary changes under steady lighting conditions. Moreover, as the pupillary response is involved in emotional (task-evoked pupillary dilation as an index of emotional arousal) and cognitive (task-evoked pupillary dilation as an index of cognitive workload) stimulation, it can be used to detect the impact of mutual subcortical and cortical structures (i.e. overlapping brain structures included in autonomic, emotional and cognitive regulation) on the pupillary innervation system. Thus, complex understanding of the baseline pupil size' and pupillary dynamics' mechanisms may provide an important insight into the central nervous system functioning pointing to the pupillometry as a promising tool in the clinical application.

\section{Key words}

Pupil size - Pupillary light reflex - Autonomic regulation • Emotional and cognitive processes $\bullet$ Clinical application

\section{Corresponding author}

Ingrid Tonhajzerova, Department of Physiology, Biomedical Center Martin, Jessenius Faculty of Medicine in Martin, Comenius University in Bratislava, Mala Hora 11161/4C, 03601 Martin, Slovak Republic. E-mail: ingrid.tonhajzerova@uniba.sk

\section{Introduction}

Autonomic nervous system (ANS) activity under central control plays a crucial role in the maintaining of body's homeostasis. However, disturbances in the central-peripheral autonomic integrity as well as dynamic imbalance between the parasympathetic and the sympathetic nervous system activity may represent important pathomechanisms in the development of various disorders (e.g. Boyce et al. 2001, Thayer et al. 2010). In this context, pupillary changes (mediated by the parasympathetic and sympathetic nervous system) commonly categorized as tonic pupil size and phasic pupillary response in the pupillometric research (Mathôt 2018), may provide a "window" into the complex psychophysiological regulatory network mechanisms. More specifically, the evaluation of the pupil size and pupillary reactivity to the light stimulation (pupillary light reflex - PLR) by automated pupillometry (enabling the quantification of the parasympathetic and the sympathetic-linked pupillary control) may provide an unique insight into autonomic regulation (Hall and Chilcott 2018). Further, as emotional and cognitive influences are commonly indexed by various 
physiological behaviors predominantly mediated by ANS, including pupillary response, the assessment of the pupillary reactivity to emotional and cognitive stimuli (i.e. task-evoked stimulation) is thus increasingly used to identify potential abnormalities in emotional/cognitive processing (Bradley et al. 2008, Einhäuser 2017). This review is aimed to summarize the significance of the changes in the pupil size/reactivity in the integrity of central autonomic, emotional, and cognitive regulation whose abnormalities are associated with various disorders, and to point out a significance of the pupillometric measurement in direct clinical application.

\section{Pupil as a window into the complex autonomic integrity}

Pupil size regulation under ambient lighting conditions

In everyday life, the pupil size is strongly influenced by the ambient lighting. Thus, the fundamental function of the autonomic pathways regulating the pupil size is to regulate the amount of light illuminating the retina. In other words, the pupil size under the global ambient lighting conditions is regulated by the balanced activity of the sympathetic and parasympathetic nervous systems. Specifically, higher levels of ambient lighting conditions predominantly lead to greater activation of the parasympathetic nervous system regulated from EdingerWestphal (E-W) nucleus resulting in the pupillary constriction. More specifically, higher lighting levels stimulate retinal photoreceptors, bipolar cells, and retinal ganglion cells. Retinal signals are transmitted to the pretectum of the mesencephalon and subsequently to the E-W nuclei in the midbrain. Preganglionic parasympathetic axons of the cholinergic neurons of E-W nuclei synapse with the ciliary ganglion neurons that send postganglionic axons innervating the iris sphincter muscle resulting in parasympathetic-mediated pupillary constriction (McDougal and Gamlin 2015). Contrary, lower levels of ambient lighting conditions lead to greater activation of the sympathetic nervous system regulated from posterior hypothalamic nuclei synapsing at the intermediolateral (IML) cell column of the cervical/thoracic spinal cord and subsequently superior cervical ganglion (SCG) that sends postganglionic axons to innervate via the ciliary nerves the contraction of the iris dilator muscle resulting in the pupillary dilation (Cherng et al. 2020). Besides relatively straightforward parasympathetic and sympathetic pathways there exist other autonomic pathways controlling pupil size that are less understood. From this aspect, pupillary constriction may also involve high levels of ambient lighting conditions-related inhibition of the sympathetic tone resulting in the iris dilator muscle relaxation. Similarly, pupillary dilation may involve low levels of ambient lighting conditions-linked parasympathetic withdrawal resulting in the iris sphincter muscle relaxation (Lowenstein and Loewenfeld 1950, McDougal and Gamlin 2015, Joshi and Gold 2020).

Pupil size regulation to standardized light stimulus pupillary light reflex

Pupillary light reflex (PLR), i.e. pupillary constriction (mediated by the contraction of the parasympathetically-innervated iris sphincter muscle) and subsequent pupillary dilation (mediated by the contraction of sympathetically-innervated iris dilator muscle) of the pupil in response to the standardized intensity and length of the light stimulation by using automated pupillometers that offer an opportunity for quantifying the parasympathetic as well as the sympathetic regulation of the pupil indexed by different PLR parameters, may provide an important metric of autonomic nervous system integrity (Girkin 2003, Hall and Chilcott 2018). Firstly, the initial pupil diameter (reflecting baseline pupil size) is assessed before measuring the dynamics of PLR consisting of pupillary response latency (time delay between the light onset and start of the constriction) followed by pupillary constriction (until the minimal pupil size is reached) and consequent pupillary redilation to the baseline pupil size (initial pupil diameter) (Hall and Chilcott 2018). Constriction phase-linked PLR parameters (i.e. parameters under direct parasympathetic control) such as absolute and relative constriction amplitude (ACA, RCA), and maximum constriction velocity (MCV) represent the most commonly used indices for detecting the parasympathetic (dys)function (Hall and Chilcott 2018, Wang et al. 2016). As sympathetic activity-linked PLR parameter we can consider the time required for the pupil diameter to return to $75 \%$ of the baseline pupil diameter from the peak of the pupillary constriction (T75) (Lowenstein and Loewenfeld 1950). In addition, Muppidi et al. (2013) proposed other indices associated with the pupillary redilation phase such as dilation velocity at T75 (DV75), and a ratio of T75 and ACA as other potential markers of the sympathetic (dys)function.

Interestingly, while the light stimulation has a robust effect on the parasympathetic activity, it has 
a dual (inhibitory and stimulatory) effect on the sympathetic activity. Thus, the sympathetic outflow is controlled by separate light-inhibited and light-stimulated pathways during the PLR. The light-inhibited sympathetic pathways originating in the retina-receptive neurons of the pretectum and the suprachiasmatic nucleus are coupled with the parasympathetic pathway mediating the PLR (Szabadi 2018). In other words, parasympathetic-linked pupillary constriction is facilitated by concurrent inhibition of the sympatheticmediated pupillary dilation (McDougal and Gamlin 2015). Further, the light-stimulated sympathetic pathways involve the noradrenergic and serotonergic ones (Szabadi 2018). The hub of the noradrenergic pathway is the locus coerulues (LC) - primary source of the noradrenaline in the central nervous system regulating thus global arousal (Aston-Jones and Waterhouse 2016) - functioning as sympathetic as well as parasympathetic nucleus. More specifically, LC contains both excitatory sympathetic neurons projecting to the sympathetic preganglionic neurons in the spinal cord and inhibitory parasympathetic neurons projecting to the E-W nucleus. The excitatory sympathetic LC neurons stimulated by the light via the retina - suprachiasmatic nucleus - dorsomedial hypothalamus - LC pathway can lead to the increased output to the pupil via $\mathrm{LC}$ - IML - SCG - dilator muscle pathway mediating the pupillary dilation (Gonzáles and Aston-Jones 2006, Szabadi 2018). The hub of serotonergic pathway is the dorsal raphe nucleus containing serotonergic neurons, some of which function as sympathetic neurons projecting to the IML where by 5 $\mathrm{HT}_{2 \mathrm{~A}}$ receptors' stimulation mediate the sympatheticlinked dilation effect on the pupil (Hornung 2003, Szabadi 2018).

\section{Pupil as an insight into central autonomic network}

Notably, the noradrenergic sympathetic pathway can be through the multiple inputs modulated by variety of physiological and psychological influences, and consequently through its outputs transmit these modulations to the pupillary response (Szabadi 2018). Further, this pathway is via LC-linked sympathetic and parasympathetic widespread connections integrated into wider central autonomic network (Samuels and Szabadi 2008, Szabadi 2013). Central autonomic network (CAN) described by Benarroch (1993) represents an integrated system of brainstem, subcortical, and cortical structures that play a key role in ANS functioning. Structurally, CAN consists of the anterior cingulate, the insular, and the ventromedial prefrontal cortices, the central nucleus of the amygdala, the paraventricular and related nuclei of the hypothalamus, the periaqueductal gray matter, the parabrachial nucleus, the nucleus of the solitary tract, the nucleus ambiguous, the ventrolateral and the ventromedial medulla, and the medullary tegmental field (Benarroch 1993). Importantly, while in the sympathetic regulation are involved the prefrontal, the anterior, and the mid cingulate, the right ventral anterior insular, and the left posterior insular cortices; the parasympathetic regulation is controlled by the cingulate cortex, the lateral temporal cortices, the bilateral dorsal insular cortices, and the hippocampus. Some regions such as the left amygdala, the right inferior parietal lobule, and a small area in the right anterior insular cortices have shown a dual role in both sympathetic and parasympathetic regulation (Beissner et al. 2013). Notably, many of the structures within the CAN overlap with important brain regions involved in other central networks such as emotional and cognitive circuits (Sklerov et al. 2019). From this perspective, autonomic pathways mediating changes of the pupil size and PLR are influenced by central emotionally/cognitively-driven descending inputs from multiple brain regions. To sum, the evaluation of the baseline pupil size and pupillary dynamics to the standardized light stimulus (by automated pupillometers) may help unravel the complexity of autonomic regulation and provide a simple, non-invasive method for broader application in the neuroscience research (Hall and Chilcott 2018), as discussed below.

\section{Pupil as a window into the cognitive and emotional processes}

\section{Baseline pupil size}

Baseline pupil diameter refers to spontaneous fluctuations in the pupil size (Peysakhovich et al. 2017). During visual experiments, the baseline pupil size indicating spontaneous fluctuations under resting-state is measured when an individual is not performing any task, often while viewing a screen with a uniform or neutral background with no meaningful stimuli to attend (except a fixation point) (Aminihajibashi et al. 2019). From psychophysiological point of view, the baseline pupil size is associated with individual cognitive-related differences in higher-order cognitive abilities such as fluid intelligence, working memory capacity, and attention control (Tsukahara et al. 2016, Tsukahara and Engle 2021, Unsworth and Robinson 2017, Unsworth et al. 
2019). Tsukahara et al. 2016 proposed that it is predominantly fluid intelligence that is linked to the baseline pupil size and that individual differences in fluid intelligence are related to the functional organisation of the resting-state brain arising from neuromodulatory role of the LC-noradrenaline system. More specifically, larger baseline pupil size may reflect stronger functional brain connectivity originating from optimal baseline activity of the LC (Tsukahara et al. 2016).

Task-evoked pupillary response to the emotional/cognitive stimuli

Task-evoked, also called event-related pupillary response usually measured as a change relative to the baseline pupil diameter, refers to the pupillary changes during the task performing and therefore is directly associated with task-related processes (Aminihajibashi et al. 2020). The most commonly observed pupillary response following emotional and cognitive stimulation is pupillary dilation that can be driven by sympathetic activation or parasympathetic inhibition (or reduced parasympathetic activation). However, the relative contributions of the sympathetic and parasympathetic nervous systems on the pupillary response induced by emotion and cognition may be different (Cherng et al. 2020). Changes of the ANS activity during the emotional processes may provide important information related to the main emotional dimensions - arousal (reflecting psychophysiological levels of activation) and valence (reflecting the appetitive and/or aversive value - pleasant vs. unpleasant - of the emotional stimuli) (Lang et al. 1993, De Zorzi et al. 2021). From this aspect, healthy individuals showed larger pupillary dilation during viewing emotionally arousing stimuli regardless of valence (positive/negative) indicating thus a pupillary dilation as an important index of emotional arousal (Bradley et al. 2008, 2017, Henderson et al. 2018, Wang et al. 2018). Moreover, Bradley et al. (2017) proposed an enhanced pupillary dilation as a single sympatheticallymediated process beginning shortly after picture onset and continuing throughout whole emotional visual stimulation interval. Greater pupillary dilation during affective pictures viewing correlated with the changes in the skin conductance response (SCR) as a peripheral index of the sympathetic activity, further supporting the hypothesis that the modulation of the pupil size during emotional processing is mediated by the sympathetic nervous system with the pupil size reported as a more reliable indicator of emotional arousal compared to SCR
(Bradley et al. 2008, 2017). More specifically, pupillary modulation during affective visual perception - pupillary dilation - begins after approximately $500 \mathrm{~ms}$ after picture onset and continues throughout the viewing interval with greater dilation for emotionally arousing pictures (scenes of erotica, mutilation, attack) compared to neutral ones in healthy individuals reflecting an effect of emotional arousal on the sympathetically-driven action of the dilator muscle (Bradley et al. 2017). SCR occurs about 1000-5000 ms after stimuli onset indicating thus the pupil response as a time-sensitive measure of autonomic arousal compared to SCR considered as a more delayed index of the sympathetic reactivity (Bradley et al. 2017, Burley and van Goozen 2020).

Similarly, task-evoked pupillary dilation was reported in association with cognitive processing. For instance, pupillary dilation was observed during memory tasks (e.g. Boyer et al. 2018), attention (e.g. Sulutvedt et al. 2018), mental arithmetic (e.g. Szulewski et al. 2017), or decision making (e.g. Van Slooten et al. 2018). Pupillary dilation during tasks requiring a high attention such as memory retrieval or mental arithmetic is predominantly suggested to be associated with the sympathetic activation (Peinkhofer et al. 2019). However, Steinhauer et al. (2004) revealed the enhanced cognitive task-related pupillary dilation in the light compared to dark lighting condition pointing to the cortical (frontal cortex) inhibitory effect on the parasympathetic-linked E$\mathrm{W}$ nucleus. Moreover, this parasympathetic inhibitionlinked pupillary dilation was clearly elucidated using pharmacological blockade of the sympathetic iris dilator muscle by dapiprazole, and was eliminated by pharmacological blockade of the parasympatheticallymediated iris sphincter muscle activity by tropicamide (Steinhauer et al. 2004). As the pupillary dilation has long been considered as an index of the cognitive load that is associated with the amount of attentional or working memory needed to perform a given task (Just et al. 2003), it can reflect the use of processing resources larger pupillary dilation is considered to correspond with greater cognitive load (Vogels et al. 2018). Interestingly, the pupillary dilation increases until the available processing capacity is filled up with the tendency to decrease when the capacity is "overloaded" (Einhäuser 2017). However, overall changes of the pupil size during cognitive stimulation seem to be too slow to accurately capture the cognitive response to stimuli that rapidly succeed each other or overlap (Vogels et al. 2018). Thus, the Index of Cognitive Activity (ICA) - number of rapid 
increases in the pupil size during a certain time period calculated from the overall pupil size - has been developed as another reliable pupillometric measure of cognitive load (Marshall 2000, 2002) which received attention only recently. It is important to note that overall pupil size changes (larger pupillary dilation) differs from ICA (that not increase, but even decrease) during increased situational demand (more difficult dual-tasking) - attentional resources distributed over multiple tasks result in decrease of rapid pupillary dilations, the ICA is thus suggested to serve as a more sensitive index of cognitive load during tasks with rapid events series or overlapping stimuli compared to overall pupil size changes (Vogels et al. 2018).

\section{Pupillary light reflex (PLR) in emotional/cognitive stimulation}

It is important to note that the emotional content (pleasant/unpleasant) of stimuli may also modulate the initial PLR primarily occurring in response to the changes in the brightness. Specifically, Henderson et al. (2014) revealed emotional-linked attenuation of the initial pupillary constriction when viewing brightness-matched erotica (pleasant) or violent (unpleasant) scenes compared to neutral ones in healthy probands. Similarly, an initial constriction of the pupil was attenuated during anticipation of aversive event such as possible presentation of an electric shock (i.e. "fear-inhibited light reflex") (Bitsios et al. 1996, 2004).

Despite the fact that previous studies revealed reduced parasympathetically-mediated PLR responses during demanding cognitive processing (Steinhauer et al. 2000), the knowledge in this area is still rare. However, PLR can be modulated by the visual awareness and visual attention (Naber et al. 2011, Mathôt and van der Stigchel 2015). More specifically, attention associated with eyemovement preparation towards a bright object is associated with pupillary constriction, probably to facilitate a rapid pupillary light response (Mathôt $e t$ al. 2015). Moreover, PLR can be modulated by a subjective perception (i.e. interpretation) of brightness overriding the effects of real light intensity (Laeng and Endestad 2012, Laeng and Sulutvedt 2014).

\section{Neuro-psycho-physiological regulatory mechanisms}

Cerebral structures involved in the modulation of the pupillary responses during cognitive and emotional processes include LC, superior colliculus, and multiple cortical regions (Peinkhofer et al. 2019), where LC seems to be the most influential mediator of the pupil size/reactivity. LC presumably function at least in two firing (tonic and phasic) modes (Aston-Jones and Cohen 2005). Tonic mode is characterized by the elevated baseline LC firing rate without phasic bursts of activity. High levels of baseline LC activity firing is linked to diffuse attention focus and increased ability to detect new stimuli. The phasic mode represents brief, rapid increases in firing rate and is associated with focused attention and behavioral responses to salient stimuli (Aston-Jones and Cohen 2005, Vazey et al. 2018). According to the Adaptive Gain Theory (Aston-Jones and Cohen 2005), LC activity can adaptively shift to a different mode (from tonic to phasic or vice versa) due to current task requirements - if attentional focus is needed on a specific task, the LC will respond with a higher frequency of phasic activity; if the task is resolved and the brain needs to be open for exploring new inputs, LC will switch to the tonic activity. In this context, as the pupil size is considered as an indirect index of LC activity, it has been proposed that tonic pupil size can reflect the tonic LC activity, while phasic pupillary response may indicate its phasic activity (Peysakhovich et al. 2017). LC-linked pupillary changes are mediated through LC-linked excitatory projections to the sympathetic IML neurons and LC-related inhibitory connections to the E-W nucleus resulting in the sympathetically-driven pupillary dilation and attenuation of the parasympathetically-mediated constriction of the PLR (Szabadi 2012). Besides the LC, the superior colliculus (SC) - a subcortical motor nucleus for saccadic eye movements and for the control of spatial selective attention (Gandhi and Katnani 2011, Krauzlis et al. 2013) - may also play an important role in the regulation of the pupil size and PLR (Wang and Munoz 2015). Specifically, SC may modulate the parasympathetic-linked pupillary size changes through direct and/or indirect (via mesencephalic cuneiform nucleus - MCN) connections with $\mathrm{E}-\mathrm{W}$ nucleus. $\mathrm{SC}$ is also (in)directly connected to LC and is influenced by descending cortical inputs from brain structures such as the frontal and the frontoparietal cortex (Joshi et al. 2016, Peinkhofer et al. 2019) potentially contributing to the modulation of the pupillary responses. Additionally, multiple cortical brain areas are involved in the modulation of the pupil size/reactivity such as frontal/prefrontal, orbitofrontal, cingulate, insular cortex (Peinkhofer et al. 2019, Joshi and Gold 2020, Fig. 1). More precisely, recent study revealed BOLD-fMRI activations correlated with changes in the pupil diameter 
within the brain regions implicated in arousal, selective attention, salience, error-detection, and decision-making such as LC, thalamus, posterior cingulate cortex, dorsal anterior cingulate and paracingulate cortex, orbitofrontal cortex, and right anterior insular cortex (DiNuzzo et al. 2019).

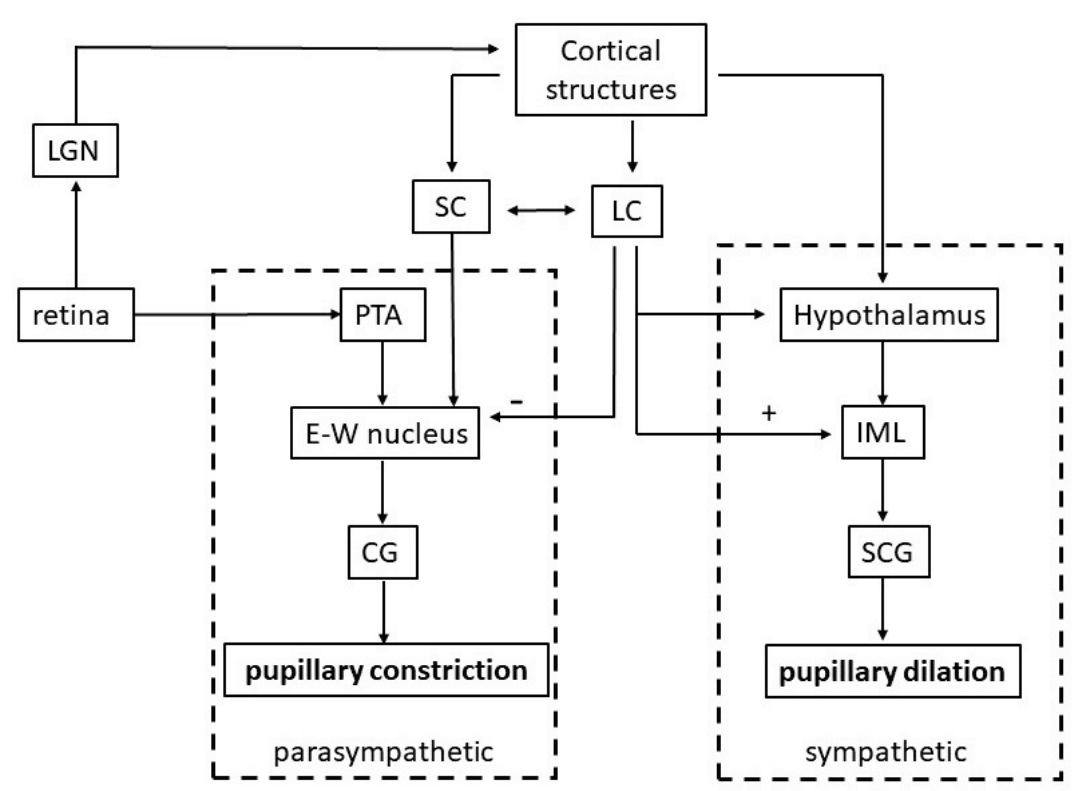

Fig. 1. Simplified schematic diagram of the cortical modulation on the pupillary innervation system. Neural pathways connecting cortical areas via subcortical structures such as locus coeruleus (LC) and superior colliculus (SC) to the pupillary innervation system are inhibitory $(-)$ and activating (+), where inputs from the locus LC inhibit parasympathetic nervous system through direct projections to the EdingerWestphal (E-W) nucleus and activate sympathetic nervous system via direct connections and indirect projections through the hypothalamus to the intermediolateral cell column of the spinal cord (IML) resulting in pupillary dilation. SC neurons via direct and indirect projections to the E-W nucleus influence the parasympathetic pupillary control. LC and SC are mutually interconnected and both structures receive multiple descending cortical inputs. LC receives descending inputs from dorsolateral and dorsomedial prefrontal cortex, anterior cingulate cortex, somatosensory, parietal and temporal cortex. SC receives inputs from visual cortex, frontal eye fields, inferior parietal cortex, ventral premotor cortex, and ventrolateral prefrontal cortex. CG - ciliary ganglion, LGN - lateral geniculate nucleus, PTA - pretectal area, SCG - superior cervical ganglion.

\section{Pupillometry - a promising diagnostic tool? (from research to clinical application)}

Pupillometry, i.e. evaluation of the baseline pupil size/phasic pupillary reactivity by eye-tracking systems, and the assessment of the PLR by using automated pupillometers, is increasingly used in the psychophysiological research (Kret and Sjak-Shie 2019, Sekaninova et al. 2019a).

\section{Pupillometry in Psychiatry}

Emotional dysregulation represents a hallmark in psychiatry. In this context, physiological changes in response to emotional stimuli are fundamental to the emotional experience, and adaptive regulation of the physiological arousal is vital for healthy functioning (Scarpa 2015). Physiological arousal increases as a result of the activation of the neural pathways in response to potentially life-threatening aversive and life-sustaining appetitive stimuli triggering a cascade of psychophysiological regulatory changes (e.g. affective, cognitive) involved in approach or avoid behavioral tendencies (Lang and Bradley 2010). Thus, abnormal physiological arousal (hypo-/hyper-arousal) in response to emotional stimuli has been associated with the onset of psychopathology (Hajcak and Patrick 2015). From this perspective, abnormal baseline pupil size as well as pupillary responses to visual (e.g. emotional) stimulation were found in individuals suffering from mental disorders such as depression, anxiety, and autism spectrum disorder (Sekaninova et al. 2019b, Kleberg et al. 2019, de Vries et al. 2021).

Pupillometric findings in autism spectrum disorder (ASD) Studies regarding evaluation of the baseline pupil size in ASD reported different patterns. While Anderson and Colombo (2009) found greater baseline pupil size in ASD children compared to aged-matched controls, Martineau et al. (2011) reported smaller baseline pupil size in ASD children. Fan et al. (2009) and Nuske et al. (2014) revealed no differences in the resting pupil size in children with and without autism. Similarly, no differences in the baseline pupil size were found between ASD adults and healthy individuals (Lawson et al. 2017). Task-evoked pupillary dilation in ASD research has been investigated as a marker of social cognition by the presentation of social cues and as a marker of sensory-perceptual processing by the presentation of basic sensory stimuli and ambiguous figures (Bast et al. 2019). Regarding social cognition, 
children with ASD showed attenuated pupillary dilation in a joint attention task, when gaze cues were incongruent to the target location (Erstenyuk et al. 2014) and to static emotional faces (Anderson et al. 2006). In addition, Aguillon-Hernandez et al. (2020) reported atypical pupillary reactivity to social stimuli in ASD with a good discriminating performance (around 75-80\%) between ASD and typically developing children. ASD adults showed attenuated pupillary dilation to static emotional faces compared to controls (Gotham et al. 2018) and attenuated pupillary dilation to observed social pain (Krach et al. 2015). Concerning sensory-perceptual processing, ASD toddlers showed increased pupillary dilation during a visual search paradigm (Blaser et al. 2014). Decreased pupillary dilation amplitudes in reaction to dark screens has been reported in ASD children compared to healthy children (DiCriscio and Troiani 2017). Study on brightness illusion in ASD adults revealed no differences in pupillary dilation compared to controls (Laeng et al. 2018). Further, Fan et al. (2009) referred to altered PLR (longer latency, smaller constriction amplitude, slower constriction velocity) in ASD children that can be used to discriminate ASD from controls with high accuracy.

\section{Pupillometric findings in major depressive disorder (MDD)}

Studies regarding child and adolescent depression are predominantly focused on task-evoked pupillary response. For instance, Silk et al. (2007) found that depressive adolescents exhibited less pupillary dilation in response to negative words compared to never depressed youth. Contrary, Burkhouse et al. (2017) revealed greater pupillary dilation in response not only to sad/fearful faces but also to happy faces in depressive adolescents. In addition, children of depressed mothers showed increased pupillary responses to sad faces (Burkhouse et al. 2014). With respect to PLR, abnormal PLR parameters (smaller percentual change of the pupil size during constriction and slower constriction velocity) was found in adolescent depression (Mestanikova et al. 2017). Interestingly, Cohen et al. (2019) found convincing evidence that individual differences in pupillary dilation uniquely predicted depression onset. Specifically, youth with subthreshold depressive symptoms and elevated pupillary dilation were over twice as likely to develop a first episode of depression (Cohen et al. 2019). Studies regarding MDD in adults reported greater baseline pupil diameter (Schumann et al. 2017) and greater pupillary dilation to negative emotional stimuli (Siegle et al. 2003) in depressive compared to never depressive adults. Further, smaller PLR-linked constriction amplitude was reported in adult depression (Bär et al. 2004).

\section{Pupillometric findings in anxiety disorders}

Pupillary responses in anxiety disorders are less studied. While Keil et al. (2018) reported blunted pupillary dilation to emotional faces in social anxiety disorder in children, another study showed greater pupillary dilation when viewing angry faces and reduced pupillary dilation to neutral faces in children with mixed anxiety disorder (Price et al. 2016). Larger pupillary dilation amplitude to happy faces in adolescent social anxiety disorder was associated with worse treatment response (Kleberg et al. 2019). In addition, children of anxious mothers exhibited increased pupillary dilation to angry faces compared to youth of non-anxious mothers (Burkhouse et al. 2014). Adults with moderate or severe anxiety showed greater pupillary dilation compared to adults with mild or no anxiety (Santos et al. 2013). Bakes et al. (1990) observed a decrease in the PLR in anxious adult patients.

\section{Pupillometry in Neurology}

From the neurological perspective, a majority of neurodegenerative diseases are characterized by abnormal accumulation of misfolded protein leading to progressive dysfunction and damage of neuron populations associated with the loss of their physiological function resulting in a wide spectrum of clinical features (Csizmok and Tompa 2008, Kovacs 2018). Specifically, the progressive loss of brain matter leads to impairments in autonomic, motor, and cognitive functions (Huang et al. 2020). From this point of view, the pupillometry may represent a suitable insight into the autonomic as well as cognitive (dys)functions.

\section{Pupillometric findings in Alzheimer's disease (AD)}

Pupil size and reactivity to the light seems to be altered in Alzheimer's disease, where AD-related neurodegeneration in LC and E-W nucleus (Bondareff et al. 1987, Scinto et al. 2001) affecting parasympathetic and sympathetic control of the pupil may play an important role. More precisely, AD patients showed reduced baseline pupil size compared to healthy individuals (Prettyman et al. 1997). Further, studies revealed increased latency of pupillary constriction, 
decreased constriction amplitude and decreased constriction velocity to the light stimulation, and faster redilation pointed to the parasympathetic dysfunction in AD patients compared to healthy individuals (as reviewed in Chougule et al. 2019).

\section{Pupillometric findings in Parkinson disease (PD)}

Studies regarding pupillary evaluation in Parkinson disease reported predominantly impaired pupillary reactivity to the light stimulation. More specifically, PD patients showed reduced constriction amplitude and prolonged constriction time of the PLR (Micieli et al. 1991). Similarly, Giza et al. (2011) reported increased latency and decreased constriction amplitude, constriction velocity, and constriction acceleration in PD patients compared to controls. Contrary, Ulep et al. (2017) found no significant differences in the PLR variables in PD patients compared to healthy probands. Studies focusing on the evaluation of the pupil size under stable lighting conditions are rare, where Tsitsi et al. (2021) reported smaller pupil size in PD patients compared to the control group.

Taken together, these pupillometric findings indicate alterations in the pupil size/reactivity in the above-mentioned disorders pointing to the pupillometry as a potentially helpful "diagnostic" tool in the clinical practice especially in the psychiatry where searching for objective biomarkers is still under intensive research.

\section{Conclusion}

In recent years, eye pupil as an easily accessible way to obtain important information regarding the human mind is gaining more attention. However, despite the intensive pupillometric research in cognitive and affective neuroscience, the exact "brain-pupil" relationships are still not well understood. Future research directions based on the complex approach of concurrent studying of the pupillometric (pupil size/reactivity), oculometric behavior (e.g. saccadic eye movements, fixations, eye blinks) in association with eye movementrelated potentials by EEG recording (Jagla 2016, Jagla et al. 2007), and functional neuroimaging may elucidate this question and also bring novel detailed insight into what happens in the brain afflicted by the disease.

\section{Conflict of Interest}

There is no conflict of interest.

\section{Acknowledgements}

This work was supported by the Slovak Scientific Grant Agency under grants VEGA 1/0030/22, VEGA $1 / 0190 / 20$, and VEGA 1/0266/18, and UK grants $\mathrm{UK} / 63 / 2021$ and UK/80/2021.

\section{References}

AGUILLON-HERNANDEZ N, MOFID Y, LATINUS M, ROCHÉ L, BUFO M R, LEMAIRE M, MALVY J, MARTINEAU J, WARDAK C, BONNET-BRILHAULT F: The pupil: a window on social automatic processing in autism spectrum disorder children J Child Psychol Psychiatry 61: 768-778, 2020. https://doi.org/10.1111/jepp. 13170

AMINIHAJIBASHI S, HAGEN T, ANDREASSEN OA, LAENG B, ESPESETH T: The effects of cognitive abilities and task demands on tonic and phasic pupil sizes. Biol Psychol 156: 1-13, 2020. https://doi.org/10.1016/j.biopsycho.2020.107945

AMINIHAJIBASHI S, HAGEN T, FOLDAL MD, LAENG B, ESPESETH T: Individual differences in resting-state pupil size: Evidence for association between working memory capacity and pupil size variability. Int $\mathrm{J}$ Psychophysiol 140: 1-7, 2019.

ANDERSON CJ, COLOMBO J: Larger tonic pupil size in young children with autism spectrum disorder. Dev Psychobiol 51: 207-211, 2009. https://doi.org/10.1002/dev.20352

ANDERSON C, COLOMBO J, SHADDY DJ: Visual scanning and pupillary responses in young children with Autism Spectrum Disorder. J Clin Exp Neuropsychol 28: 1238-1256, 2006. https://doi.org/10.1080/13803390500376790

ASTON-JONES G, COHEN JD: An integrative theory of locus coeruleus-norepinephrine function: adaptive gain and optimal performance. Annu Rev Neurosci 28: 403-450, 2005. https://doi.org/10.1146/annurev.neuro.28.061604.135709 
ASTON-JONES G, WATERHOUSE B: Locus coeruleus: from global projection system to adaptive regulation of behavior. Brain Res 1645: 75-78, 2016. https://doi.org/10.1016/j.brainres.2016.03.001

BAKES A, BRADSHAW C, SZABADI E: Attenuation of the pupillary light reflex in anxious patients. Br J Clin Pharmacol 30: 377-381, 1990. https://doi.org/10.1111/j.1365-2125.1990.tb03787.x

BAST N, BANASCHEWSKI T, DZIOBEK I, BRANDEIS D, POUSTKA L, FREITAG CM: Pupil Dilation Progression Modulates Aberrant Social Cognition in Autism Spectrum Disorder. Autism Res 12: 1680-1692, 2019. https://doi.org/10.1002/aur.2178

BÄR K J, GREINER W, JOCHUM T, FRIEDRICH M, WAGNER G, SAUER H: The influence of major depression and its treatment on heart rate variability and pupillary light reflex parameters. J Affect Disord 82: 245-252, 2004. https://doi.org/10.1016/j.jad.2003.12.016

BEISSNER F, MEISSNER K, BAR KJ, NAPADOW V: The autonomic brain: an activation likelihood estimation meta-analysis for central processing of autonomic function. J Neurosci 33: 10503-10511, 2013. https://doi.org/10.1523/JNEUROSCI.1103-13.2013

BENARROCH EE: The central autonomic network: functional organization, dysfunction, and perspective. Mayo Clin Proc 68: 988-1001, 1993. https://doi.org/10.1016/s0025-6196(12)62272-1

BERTRAND AL, BATISTA J, GARCIA S, VIERA EB, SANTOS AM, BERTRAND RH: Pupillometry: The Influence of Gender and Anxiety on the Pain Response. Pain Physician 16: 257-266, 2013.

BITSIOS P, SZABADI E, BRADSHAW CM: The fear-inhibited light reflex: Importance of the anticipation of an aversive event. Int J Psychophysiol 52: 87-95, 2004. https://doi.org/10.1016/j.ijpsycho.2003.12.006

BITSIOS P, SZABADI E, BRADSHAW CM: The inhibition of the pupillary light reflex by the threat of an electric shock: a potential laboratory model of human anxiety. J Psychopharmacol 10: 279-287, 1996. https://doi.org/10.1177/026988119601000404

BLASER E, EGLINGTON L, CARTER AS, KALDY Z: Pupillometry reveals a mechanism for the Autism Spectrum Disorder (ASD) advantage in visual tasks. Sci Rep 4: 1-5, 2014. https://doi.org/10.1038/srep04301

BONDAREFF W, MOUNTJOY CQ, ROTH M, ROSSOR MN, IVERSEN LL, REYNOLDS GP, HAUSER DL: Neuronal degeneration in locus ceruleus and cortical correlates of Alzheimer disease. Alzheimer Dis Assoc Disord 1: 256-262, 1987. https://doi.org/10.1097/00002093-198701040-00005

BOYCE WT, QUAS J, ALKON A, SMIDER NA, ESSEX MJ, KUPFER DJ, ABLOW JC, ARMSTRONG JM, GOLDSTEIN LH, HARRINGTON R, KRAEMER HC, MEASELLE JR, NELSON C, STEINBERG L: Autonomic reactivity and psychopathology in middle childhood. Br J Psychiatry 179: 144-150, 2001. https://doi.org/10.1192/bjp.179.2.144

BOYER S, PAUBEL PV, RUIZ R, YAGOUBI RE, DAURAT A: Human voice as a measure of mental load level. J Speech Lang Hear Res 61: 2722-2734, 2018. https://doi.org/10.1044/2018_JSLHR-S-18-0066

BRADLEY MM, MICCOLI L, ESCRIG MA, LANG PJ: The pupil as a measure of emotional arousal and autonomic activation. Psychophysiology 45: 602-607, 2008. https://doi.org/10.1111/j.1469-8986.2008.00654.x

BRADLEY MM, SAPIGAO RG, LANG PJ: Sympathetic ANS modulation of pupil diameter in emotional scene perception: effects of hedonic content, brightness, and contrast. Psychophysiology 54: 1419-1435, 2017. https://doi.org/10.1111/psyp. 12890

BURKHOUSE KL, OWENS M, FEURER C, SOSOO E, KUDINOVA A, GIBB BE: Increased neural and pupillary reactivity to emotional faces in adolescents with current and remitted major depressive disorder. Soc Cogn Affect Neurosci 12: 783-792, 2017. https://doi.org/10.1093/scan/nsw184

BURKHOUSE KL, SIEGLE GJ, GIBB BE: Pupillary reactivity to emotional stimuli in children of depressed and anxious mothers. J Child Psychol Psychiatry 55: 1009-1016, 2014. https://doi.org/10.1111/jcpp.12225

BURLEY DT, VAN GOOZEN SH: Pupil response to affective stimuli: a biomarker of early conduct problems in young children. J Abnorm Child Psychol 48: 693-701, 2020. https://doi.org/10.1007/s10802-020-00620-Z

CHERNG YG, BAIRD T, CHEN JT, WANG CA: Background luminance effects on pupil size associated with emotion and saccade preparation. Sci Rep 10: 15718, 2020. https://doi.org/10.1038/s41598-020-72954-Z

CHOUGULE PS, NAJJAR RP, FINKELSTEIN MT, KANDIAH N, MILEA D: Light-induced pupillary responses in Alzheimer's disease. Front Neurol 10: 1-12, 2019. https://doi.org/10.3389/fneur.2019.00360 
COHEN JR, THAKUR H, BURKHOUSE KL, GIBB BE: A Multi-Method Screening Approach for Pediatric Depression Onset: An Incremental Validity Study. J Consult Clin Psychol 87: 184-197, 2019. https://doi.org/10.1037/ccp0000364

CSIZMÓK V, TOMPA P: Structural Disorder and Its Connection with Misfolding Diseases. In Protein Folding and Misfolding: Neurodegenerative Diseases. J OVÁDI, F OROSZ (eds), Springer, Netherlands, 2008, pp 1-19.

DE VRIES L, FOUQUAET I, BOETS B, NAULAERS G, STEYAERT J: Autism spectrum disorder and pupillometry: a systematic review and meta-analysis. Neurosci Biobehav Rev 120: 479-508, 2021. https://doi.org/10.1016/j.neubiorev.2020.09.032

DE ZORZI L, RANFAING S, HONORÉ J, SEQUEIRA H: Autonomic reactivity to emotion: A marker of sub-clinical anxiety and depression symptoms? Psychophysiology 58: e13774, 2021. https://doi.org/10.1111/psyp.13774

DICRISCIO AS, TROIANI V: Pupil adaptation corresponds to quantitative measures of autism traits in children. Sci Rep 7: 6476, 2017. https://doi.org/10.1038/s41598-017-06829-1

DINUZZO M, MASCALI D, MORASCHI M, BUSSU G, MAUGERI L, MANGINI F, FRATINI M, GIOVE F: Brain networks underlying eye's pupil dynamics. Front Neurosci 13: 965, 2019. https://doi.org/10.3389/fnins.2019.00965

EINHÄUSER W: The pupil as marker of cognitive processes. In Computational and Cognitive Neuroscience of Vision. ZHAO Q (ed), Springer International Publishing, New York, 2017, pp 141-169. https://doi.org/10.1007/978981-10-0213-7 7

ERSTENYUK V, SWANSON MR, SILLER M: Pupillary responses during a joint attention task are associated with nonverbal cognitive abilities and sub-clinical symptoms of autism. Res Autism Spectr Disord 8: 644-653, 2014. https://doi.org/10.1016/j.rasd.2014.03.003

FAN X, MILES JH, TAKAHASHI N, YAO G: Abnormal transient pupillary light reflex in individuals with autism spectrum disorders. J Autism Dev Disord 39: 1499-1508, 2009. https://doi.org/10.1007/s10803-009-0767-7

GAJARDO AI, MADARIAGA S, MALDONADO PE: Autonomic nervous system assessment by pupillary response as a potential biomarker for cardiovascular risk: a pilot study. J Clin Neurosci 59: 41-46, 2019. https://doi.org/10.1016/i.jocn.2018.11.015

GANDHI NJ, KATNANI HA: Motor functions of the superior colliculus. Annu Rev Neurosci 34: 205-231, 2011. https://doi.org/10.1146/annurev-neuro-061010-113728

GARCÍA-GÓMEZ RG, LÓPEZ-JARAMILLO P, TOMAZ C: The role played by the autonomic nervous system in the relation between depression and cardiovascular disease. Rev Neurol 44: 225-233, 2007. https://doi.org/10.33588/rn.4404.2006328

GIRKIN CA: Evaluation of the pupillary light response as an objective measure of visual function. Ophthalmol Clin North Am 16: 143-153, 2003. https://doi.org/10.1016/s0896-1549(03)00002-6

GIUBILEI F, STRANO S, IMBIMBO BP, TISEI P, CALCAGNINI G, LINO S, FRONTONI M, SANTINI M, FIESCHI C: Cardiac Autonomic Dysfunction in Patients with Alzheimer Disease: Possible Pathogenetic Mechanisms. Alzheimer Dis Assoc Disord 12: 356-361, 1998. https://doi.org/10.1097/00002093-199812000$\underline{00017}$

GiZA E, FOtiou D, BOStAntJopoulou S, KATSAROU Z, KARLOVASITOU A: Pupil light reflex in Parkinson's disease: Evaluation with pupillometry. Int J Neurosci 121: 37-43, 2011. https://doi.org/10.3109/00207454.2010.526730

GONZÁLEZ MM, ASTON-JONES G: Circadian regulation of arousal: Role of the noradrenergic locus coeruleus system and light exposure. Sleep 29: 1327-1336, 2006. https://doi.org/10.1093/sleep/29.10.1327

GOTHAM KO, SIEGLE GJ, HAN GT, TOMARKEN AJ, CRIST RN, SIMON DM, BODFISH JW: Pupil response to social-emotional material is associated with rumination and depressive symptoms in adults with autism spectrum disorder. PLoS One 13: e0200340, 2018. https://doi.org/10.1371/journal.pone.0200340

HAJCAK G, PATRICK CJ: Situating psychophysiological science within the Research Domain Criteria (RDoC) framework. Int J Psychophysiol 98: 223-226, 2015. https://doi.org/10.1016/j.ijpsycho.2015.11.001

HALL CA, CHILCOTT RP: Eyeing up the future of the pupillary light reflex in neurodiagnostics. Diagnostics 8: 19, 2018. https://doi.org/10.3390/diagnostics8010019 
HENDERSON RR, BRADLEY MM, LANG PJ: Emotional imagery and pupil diameter. Psychophysiology 55: e13050, 2018. https://doi.org/10.1111/psyp.13050

HENDERSON RR, BRADLEY MM, LANG PJ: Modulation of the initial light reflex during affective picture viewing. Psychophysiology 51: 815-818, 2014. https://doi.org/10.1111/psyp.12236

HORNUNG JP: The human raphe nuclei and the serotonergic system. J Chemical Neuroanat 26: 331-343, 2003. https://doi.org/10.1016/j.jchemneu.2003.10.002

HUANG J, COE B, SMORENBURG M, BRIEN D, BLACK S, FINGER E, FREEDMAN M, LANG A, STRONG M, SWARTZ R, TARTAGLIA C, ZINMAN L, MUNOZ D: Altered Pupil Dynamics in Patients with Neurodegenerative Diseases. Neurology 94: 1641, 2020.

JAGLA F: Saccadic eye movements as a marker of mental disorders. Physiol Res 65: 365-371, 2016. https://doi.org/10.33549/physiolres.933435

JAGLA F, JERGELOVA M, RIECANSKY I: Saccadic eye movement related potentials. Physiol Res 56: 707-713, 2007.

JOSHI S, GOLD JI: Pupil size as a window on neural substrates of cognition. Trends Cogn Sci 24: 466-480, 2020. https://doi.org/10.1016/j.tics.2020.03.005

JOSHI S, LI Y, KALWANI RM, GOLD JI: Relationships between pupil diameter and neuronal activity in the locus coeruleus, colliculi, and cingulate cortex. Neuron 89: 221-34, 2016. https://doi.org/10.1016/j.neuron.2015.11.028

JUST MA, CARPENTER PA, MIYAKE A: Neuroindices of cognitive workload: Neuroimaging, pupillometric and event-related potential studies of brain work. Theor Issues Ergon Sci 4: 59-88, 2003. https://doi.org/10.1080/14639220210159735

KEIL V, HEPACH R, VIERRATH S, CAFFIER D, TUSCHEN-CAFFIER B, KLEIN C, SCHMITZ J: Children with social anxiety disorder show blunted pupillary reactivity and altered eye contact processing in response to emotional faces: Insights from pupillometry and eye movements. J Anxiety Disord 58: 61-69, 2018. https://doi.org/10.1016/j.janxdis.2018.07.001

KLEBERG JL, HANQVIST C, SERLACHIUS E, HÖGSTRÖM J: Pupil dilation to emotional expressions in adolescent social anxiety disorder is related to treatment outcome. J Anxiety Disord 65: 26-33, 2019. https://doi.org/10.1016/j.janxdis.2019.04.006

KOVACS GG: Concepts and classification of neurodegenerative diseases. Handb Clin Neurol 145: 301-307, 2018. https://doi.org/10.1016/B978-0-12-802395-2.00021-3

KRACH S, KAMP-BECKER I, EINHÄUSER W, SOMMER J, FRÄSSLE S, JANSEN A, RADEMACHER L, MÜLLER-PINZLER L, GAZZOLA V, PAULUS FM: Evidence from pupillometry and fMRI indicates reduced neural response during vicarious social pain but not physical pain in autism. Hum Brain Mapp 36: 4730-4744, 2015. https://doi.org/10.1002/hbm.22949

KRAUZLIS RJ, LOVEJOY LP, ZENON A: Superior colliculus and visual spatial attention. Annu Rev Neurosci 36: 165-182, 2013.

KRET ME, SJAK-SHIE EE: Preprocessing pupil size data: guidelines and code. Behav Res Methods 51: 1336-1342, 2019. https://doi.org/10.3758/s13428-018-1075-y

LAENG B, ENDESTAD T: Bright illusions reduce the eye's pupil. Proc Natl Acad Sci USA 109: 2162-2167, 2012. https://doi.org/10.1073/pnas.1118298109

LAENG B, FÆREVAAG F S, TANGGAARD S, VON TETZCHNER S: Pupillary Responses to Illusions of Brightness in Autism Spectrum Disorder. Iperception 9: 2041669518771716, 2018. https://doi.org/10.1177/2041669518771716

LAENG B, SUlUTVEDT U: The Eye Pupil Adjusts to Imaginary Light. Psychol Sci 25: 188-197, 2014. https://doi.org/10.1177/0956797613503556

LANG PJ, BRADLEY MM: Emotion and the motivational brain. Biol Psychol 84: 437-450, 2010. https://doi.org/10.1016/j.biopsycho.2009.10.007

LANG PJ, GREENWALD MK, BRADLEY MM, HAMM AO: Looking at pictures: affective, facial, visceral, and behavioral reactions. Psychophysiology 30: 261-273, 1993. https://doi.org/10.1111/j.14698986.1993.tb03352.x 
LAWSON RP, MATHYS C, REES G: Adults with autism overestimate the volatility of the sensory environment. Nat Neurosci 20: 1293-1299, 2017. https://doi.org/10.1038/nn.4615

LOWENSTEIN O, LOEWENFELD IE: Role of sympathetic and parasympathetic systems in reflex dilatation of the pupil: pupillographic studies. Arch Neurol Psychiatry 64: 313-340, 1950. https://doi.org/10.1001/archneurpsyc. 1950.02310270002001

MARSHALL SP: Method and apparatus for eye tracking and monitoring pupil dilation to evaluate cognitive activity. Patent US-6090051-A, 2000.

MARSHALL SP: The Index of Cognitive Activity: measuring cognitive workload. $7^{\text {th }}$ IEEE Conference on Human Factors and Power Plants, Scottsdale, Arizona, 2002, pp 75-79. https://doi.org/10.1109/HFPP.2002.1042860

MARTINEAU J, HERNANDEZ N, HIEBEL L, ROCHÉ L, METZGER A, BONNET-BRILHAULT F: Can pupil size and pupil responses during visual scanning contribute to the diagnosis of autism spectrum disorder in children? J Psychiatr Res 45: 1077-1082, 2011. https://doi.org/10.1016/j.jpsychires.2011.01.008

MATHÔT S: Pupillometry: Psychology, Physiology, and Function. J Cogn 1: 1-23, 2018. http://doi.org/10.5334/joc.18

MATHÔT S, VAN DER LINDEN L, GRAINGER J, VITU F: The pupillary light response reflects eye-movement preparation. J Exp Psychol Hum Percept Perform 41: 28-35, 2015. https://doi.org/10.1037/a0038653

MATHÔT S, VAN DER STIGCHEL S: New Light on the Mind's Eye: The Pupillary Light Response as Active Vision. Curr Dir Psychol Sci 24: 374-378, 2015. https://doi.org/10.1177/0963721415593725

MCDOUGAL DH, GAMLIN PD: Autonomic control of the eye. Compr Physiol 5: 439-473, 2015. https://doi.org/10.1002/cphy.c140014

MESTANIKOVA A, ONDREJKA I, MESTANIK M, CESNEKOVA D, VISNOVCOVA Z, BUJNAKOVA I, OPPA M, CALKOVSKA A, TONHAJZEROVA I: Pupillary light reflex is altered in adolescent depression. Physiol Res 66: 277-284, 2017. https://doi.org/10.33549/physiolres.933683

MICIELI G, TASSORELLI C, MARTIGNONI E, PACCHETTI C, BRUGGI P, MAGRI M, NAPPI G: Disordered pupil reactivity in Parkinson's disease. Clin Auton Res 1: 55-58, 1991. https://doi.org/10.1007/BF01826058

MUPPIDI S, ADAMS-HUET B, TAJZOY E, SCRIBNER M, BLAZEK P, SPAETH EB, FROHMAN E, DAVIS S, VERNINO S: Dynamic pupillometry as an autonomic testing tool. Clin Auton Res 23: 297-303, 2013. https://doi.org/10.1007/s10286-013-0209-7

NABER M, FRÄSSLE S, EINHÄUSER W: Perceptual rivalry: Reflexes reveal the gradual nature of visual awareness. PLoS One 6: e20910, 2011. https://doi.org/10.1371/journal.pone.0020910

NUSKE HJ, VIVANTI G, DISSANAYAKE C: Brief report: Evidence for normative resting-state physiology in autism. J Autism Dev Disord 44: 2057-2063, 2014. https://doi.org/10.1007/s10803-014-2068-Z

PEINKHOFER C, KNUDSEN GM, MORETTI R, KONDZIELLA D: Cortical modulation of pupillary function: systematic review. PeerJ 7: e6882, 2019. https://doi.org/10.7717/peerj.6882

PEYSAKHOVICH V, VACHON F, DEHAIS F: The impact of luminance on tonic and phasic pupillary responses to sustained cognitive load. Int J Psychophysiol 112: 40-45, 2017. https://doi.org/10.1016/j.ijpsycho.2016.12.003

PRETTYMAN R, BITSIOS P, SZABADI E. Altered pupillary size and darkness and light reflexes in Alzheimer's disease. J Neurol Neurosurg Psychiatry 62: 665-668, 1997.

PRICE RB, ROSEN D, SIEGLE GJ, LADOUCEUR CD, TANG K, ALLEN KB, RYAN ND, DAHL RE, FORBES EE, SILK JS: From anxious youth to depressed adolescents: Prospective prediction of 2-year depression symptoms via attentional bias measures. J Abnorm Psychol 125: 267-278, 2016. https://doi.org/10.1037/abn0000127

SAMUELS E, SZABADI E: Functional neuroanatomy of the noradrenergic locus coeruleus: its roles in the regulation of arousal and autonomic function part ii: physiological and pharmacological manipulations and pathological alterations of locus coeruleus activity in humans. Curr Neuropharmacol 6: 254-285, 2008. https://doi.org/10.2174/157015908785777193

SCARPA A: Physiological arousal and its dysregulation in child maladjustment. Curr Dir Psychol Sci 24: 345-351, 2015. https://doi.org/10.1177/0963721415588920

SCHUMANN A, ANDRACK C, BÄR KJ: Differences of sympathetic and parasympathetic modulation in major depression. Prog Neuropsychopharmacol Biol Psychiatry 79: 324-331, 2017. https://doi.org/10.1016/j.pnpbp.2017.07.009 
SCINTO LF, FROSCH M, WU CK, DAFFNER KR, GEDI N, GEULA C. Selective cell loss in Edinger-Westphal in asymptomatic elders and Alzheimer's patients. Neurobiol Aging 22: 729-736, 2001. https://doi.org/10.1016/s0197-4580(01)00235-4

SEKANINOVA N, MESTANIK M, MESTANIKOVA A, HAMRAKOVA A, TONHAJZEROVA I: Novel approach to evaluate central autonomic regulation in attention deficit/hyperactivity disorder (ADHD). Physiol Res 68: 531-545, 2019a. https://doi.org/10.33549/physiolres.934160

SEKANINOVA N, ONDREJKA I, BONA OLEXOVA L, VISNOVCOVA Z, MESTANIK M, CESNEKOVA D, HAMRAKOVA A, TONHAJZEROVA I: Oculometric behavior assessed by pupil response is altered in adolescent depression. Physiol Res 68: S325-338, 2019b. https://doi.org/10.33549/physiolres.934359

SIEGLE GJ, STEINHAUER SR, CARTER CS, RAMEL W, THASE ME: Do the Seconds Turn Into Hours? Relationships between Sustained Pupil Dilation in Response to Emotional Information and Self-Reported Rumination. Cognit Ther Res 27: 365-382, 2003. https://doi.org/10.1023/A:1023974602357.

SILK JS, DAHL RE, RYAN ND, FORBES EE, AXELSON DA, BIRMAHER B, SIEGLE GJ: Pupillary reactivity to emotional information in child and adolescent depression: links to clinical and ecological measures. Am J Psychiatry 164: 1873-1880, 2007. https://doi.org/10.1176/appi.ajp.2007.06111816

SKLEROV M, DAYAN E, BROWNER N: Functional neuroimaging of the central autonomic network: recent developments and clinical implications. Clin Auton Res 29: 555-566, 2019. https://doi.org/10.1007/s10286$\underline{018-0577-0}$

STEINHAUER SR, CONDRAY R, KASPAREK A: Cognitive modulation of midbrain function: task-induced reduction of the pupillary light reflex. Int J Psychophysiol 39: 21-30, 2000. https://doi.org/10.1016/s0167$\underline{8760(00) 00119-7}$

STEINHAUER SR, SIEGLE GJ, CONDRAY R, PLESS M: Sympathetic and parasympathetic innervation of pupillary dilation during sustained processing. Int J Psychophysiol 52: 77-86, 2004. https://doi.org/10.1016/j.ijpsycho.2003.12.005

SULUTVEDT U, MANNIX TK, LAENG B: Gaze and the eye pupil adjust to imagined size and distance. Cogn Sci 42: 3159-3176, 2018. https://doi.org/10.1111/cogs.12684

SZABADI E: Functional organization of the sympathetic pathways controlling the pupil: light-inhibited and lightstimulated pathways. Front Neurol 9: 1069, 2018. https://doi.org/10.3389/fneur.2018.01069

SZABADI E: Functional neuroanatomy of the central noradrenergic system. J Psychopharmacol 27: 659-693, 2013. https://doi.org/10.1177/0269881113490326

SZABADI E: Modulation of physiological reflexes by pain: role of the locus coeruleus. Front Integr Neurosci 6: 94, 2012. https://doi.org/10.3389/fnint.2012.00094

SZULEWSKI A, GEGENFURTNER A, HOWES DW, SIVILOTTI ML, VAN MERRIËNBOER JJ: Measuring physician cognitive load: validity evidence for a physiologic and a psychometric tool. Adv Heal Sci Educ 22: 951-968, 2017. https://doi.org/10.1007/s10459-016-9725-2

THAYER JF, YAMAMOTO SS, BROSSCHOT JF: The relationship of autonomic imbalance, heart rate variability and cardiovascular disease risk factors. Int J Cardiol 141: 122-131, 2010. https://doi.org/10.1016/j.ijcard.2009.09.543

TSITSI P, BENFATTO MN, SEIMYR GÖ, LARSSON O, SVENNINGSSON P, MARKAKI I: Fixation Duration and Pupil Size as Diagnostic Tools in Parkinson's Disease. J Parkinsons Dis 11: 865-875, 2021. https://doi.org/10.3233/JPD-202427

TSUKAHARA JS, ENGLE RW: Is baseline pupil size related to cognitive ability? Yes (under proper lighting conditions). Cognition 211: 1-19, 2021. https://doi.org/10.1016/j.cognition.2021.104643

TSUKAHARA JS, HARRISON TL, ENGLE RW: The relationship between baseline pupil size and intelligence. Cogn Psychol 91: 109-123, 2016. https://doi.org/10.1016/j.cogpsych.2016.10.001

ULEP R, KHAN F, HOUGHTON D: Comparison of quantitative measures of Pupil Light Reflex measured using Automated Pupillometer in patients with Parkinson's disease and controls. Neurology 88: P1.014, 2017.

UNSWORTH N, ROBINSON MK: A locus coeruleus-norepinephrine account of individual differences in working memory capacity and attention control. Psychon Bull Rev 24: 1282-1311, 2017. https://doi.org/10.3758/s13423-016-1220-5 
UNSWORTH N, ROBISON MK, MILLER AL: Individual differences in baseline oculometrics: Examining variation in baseline pupil diameter, spontaneous eye blink rate, and fixation stability. Cogn Affect Behav Neurosci 19: 1074-1093, 2019. https://doi.org/10.3758/s13415-019-00709-z

VAN SLOOTEN JC, JAHFARI S, KNAPEN T, THEEUWES J: How pupil responses track value-based decisionmaking during and after reinforcement learning. PLoS Comput Biol 14: e1006632, 2018. https://doi.org/10.1371/journal.pcbi.1006632

VAZEY EM, MOORMAN DE, ASTON-JONES G: Phasic locus coeruleus activity regulates cortical encoding of salience information. Proc Natl Acad Sci USA 115: 9439-9448, 2018. https://doi.org/10.1073/pnas.1803716115

VOGELS J, DEMBERG V, KRAY J: The index of cognitive activity as a measure of cognitive processing load in dual task settings. Front Psychol 9: 2276, 2018. https://doi.org/10.3389/fpsyg.2018.02276

WANG CA, BAIRD T, HUANG J, COUTINHO JD, BRIEN DC, MUNOZ DP: Arousal Effects on Pupil Size, Heart Rate, and Skin Conductance in an Emotional Face Task. Front Neurol 9: 1029, 2018. https://doi.org/10.3389/fneur.2018.01029

WANG CA, MUNOZ DP: A circuit for pupil orienting responses: implications for cognitive modulation of pupil size. Curr Opin Neurobiol 33: 134-140, 2015. https://doi.org/10.1016/j.conb.2015.03.018

WANG Y, ZEKVELD A A, NAYLOR G, OHLENFORST B, JANSMA E P, LORENS A, LUNNER T, KRAMER SE: Parasympathetic Nervous System Dysfunction, as Identified by Pupil Light Reflex, and Its Possible Connection to Hearing Impairment. PLoS One 11: e0153566, 2016. https://doi.org/10.1371/journal.pone.0153566

ZIEMSSEN T, REICHMANN H: Cardiovascular autonomic dysfunction in Parkinson's disease. J Neurol Sci 289: 74-80, 2010. https://doi.org/10.1016/i.jns.2009.08.031 